\title{
Hypoxic stress in diabetic pregnancy contributes to impaired embryo gene expression and defective development by inducing oxidative stress
}

\author{
Rulin Li, ${ }^{1,2}$ Martha Chase, ${ }^{1}$ Sung-Kwon Jung, ${ }^{3}$ Peter J. S. Smith, ${ }^{3}$ and Mary R. Loeken ${ }^{1,2}$ \\ ${ }^{1}$ Section on Developmental and Stem Cell Biology, Joslin Diabetes Center, Boston; ${ }^{2}$ Department \\ of Medicine, Harvard Medical School, Boston; and ${ }^{3}$ BioCurrents Research Center, \\ Program in Molecular Physiology, Marine Biological Laboratory, Woods Hole, Massachusetts
}

Submitted 16 September 2004; accepted in final form 25 May 2005

\begin{abstract}
Li, Rulin, Martha Chase, Sung-Kwon Jung, Peter J. S. Smith, and Mary R. Loeken. Hypoxic stress in diabetic pregnancy contributes to impaired embryo gene expression and defective development by inducing oxidative stress. Am J Physiol Endocrinol Metab 289: E591-E599, 2005. First published May 31, 2005; doi:10.1152/ajpendo.00441.2004.-We have shown that neural tube defects (NTD) in a mouse model of diabetic embryopathy are associated with deficient expression of $\operatorname{Pax} 3$, a gene required for neural tube closure. Hyperglycemia-induced oxidative stress is responsible. Before organogenesis, the avascular embryo is physiologically hypoxic $\left(2-5 \% \mathrm{O}_{2}\right)$. Here we hypothesized that, because $\mathrm{O}_{2}$ delivery is limited at this stage of development, excess glucose metabolism could accelerate the rate of $\mathrm{O}_{2}$ consumption, thereby exacerbating the hypoxic state. Because hypoxia can increase mitochondrial superoxide production, excessive hypoxia may contribute to oxidative stress. To test this, we assayed $\mathrm{O}_{2}$ flux, an indicator of $\mathrm{O}_{2}$ availability, in embryos of glucose-injected hyperglycemic or saline-injected mice. $\mathrm{O}_{2}$ flux was reduced by $30 \%$ in embryos of hyperglycemic mice. To test whether hypoxia replicates, and hyperoxia suppresses, the effects of maternal hyperglycemia, pregnant mice were housed in controlled $\mathrm{O}_{2}$ chambers on embryonic day 7.5 . Housing pregnant mice in $12 \%$ $\mathrm{O}_{2}$, or induction of maternal hyperglycemia $(>250 \mathrm{mg} / \mathrm{dl})$, decreased Pax3 expression fivefold, and increased NTD eightfold. Conversely, housing pregnant diabetic mice in $30 \% \mathrm{O}_{2}$ significantly suppressed the effect of maternal diabetes to increase NTD. These effects of hypoxia appear to be the result of increased production of mitochondrial superoxide, as indicated by assay of lipid peroxidation, reduced glutathione, and $\mathrm{H}_{2} \mathrm{O}_{2}$. Further support of this interpretation was the effect of antioxidants, which blocked the effects of maternal hypoxia, as well as hyperglycemia, on Pax3 expression and NTD. These observations suggest that maternal hyperglycemia depletes $\mathrm{O}_{2}$ in the embryo and that this contributes to oxidative stress and the adverse effects of maternal hyperglycemia on embryo development.
\end{abstract}

diabetic embryopathy; neural tube; hypoxia; Pax3

DIABETIC EMBRYOPATHY IS A COMPLICATION of diabetes in which the embryo of a diabetic mother develops congenital malformations. Diabetic pregnancy-induced malformations arise at the earliest stages of organogenesis, corresponding to approximately the first $8 \mathrm{wk}$ of human gestation (36). Virtually any organ system is subject to malformation, but the neural tube and the heart are most commonly affected $(4,37)$. Offspring of women with either type 1 or type 2 diabetes are at risk for diabetic embryopathy (51), suggesting that hyperglycemia, and consequent increased glucose transport to the embryo, is responsible.

Address for reprint requests and other correspondence: M. R. Loeken, Joslin Diabetes Center, One Joslin Pl., Boston, MA 02215 (e-mail: Mary.loeken@joslin. harvard.edu).
To understand the biochemical and molecular mechanisms by which maternal hyperglycemia leads to congenital malformations, we have employed a mouse model of diabetic pregnancy that leads to a significant increase in neural tube defects (NTD; see Ref. 41). We have shown that maternal diabetes induced by streptozotocin (STZ), or transient induction of hyperglycemia ( $\geq 13.9 \mathrm{mM}$ ) by glucose injection on embryonic day 7.5 leads to decreased expression of Pax3 beginning on day 8.5 and increased incidence of NTD, which can be recognized by day 10.5 (20, 41). Pax3 encodes a transcription factor that is expressed in neuroepithelium, neural crest, and somitic mesoderm (24). Homozygous Splotch embryos ( $\mathrm{Sp} / \mathrm{Sp}$ ) carry loss of functional Pax3 alleles and develop defects of the neural tube (exencephaly, spina bifida, or both), neural crest, and skeletal muscle with $100 \%$ penetrance $(3,7,17,23)$. They die by day 16.5 of gestation, resulting from defective migration of neural crest cells to the heart (13). Heterozygous $\mathrm{Sp} /+$ mice are viable, although they are recognizable by white patches of fur resulting from maldevelopment of neural crest-derived melanocytes. Because the exencephaly affecting embryos of diabetic mice and $S p / S p$ embryos are morphologically quite similar, this suggests that deficient expression of Pax3 phenocopies Pax3 loss-of-function mutations. Undoubtedly, there are other genes in which expression could be inhibited by maternal diabetes and lead to defects of other organs or contribute to NTD. However, because Pax3 is an absolutely essential gene for development, if its expression alone is reduced below a critical threshold, an NTD will occur. Therefore, investigating how Pax3 is regulated by maternal diabetes is itself important, and may serve as a general model of how embryo gene expression is disturbed during diabetic pregnancy.

Many studies using rodent embryos have shown that reactive oxygen species are increased by maternal diabetes or highglucose culture and that administration of antioxidants, or transgenic overexpression of $\mathrm{Cu}^{2+} / \mathrm{Zn}^{2+}$ superoxide dismutase, can prevent hyperglycemia-induced developmental defects $(12,18,19,25,42,46,47,54)$. We showed that oxidative stress, caused by maternal diabetes or administration of antimycin A (AA), a mitochondrial complex III inhibitor that increases superoxide production (52), inhibits Pax3 expression and increases NTD (12). Increased oxidant status is likely to be complex, involving a combination of increased superoxide production as well as impaired free radical scavenging, and the pathways responsible for increased oxidant status have not been completely elucidated.

\footnotetext{
The costs of publication of this article were defrayed in part by the payment of page charges. The article must therefore be hereby marked "advertisement" in accordance with 18 U.S.C. Section 1734 solely to indicate this fact.
} 
The stage of early postimplantation development that is vulnerable for induction of NTD is just before the development of the circulatory system and coincides with a stage of development in which the embryo is relatively hypoxic $\left(2-8 \% \mathrm{O}_{2}\right.$, compared with $20 \%$ in maternal arterial circulation; see Refs. 21 and 44). Indeed, delivery of $\mathrm{O}_{2}$ is diffusion limited, and the increasing mass of the embryo causes a state of physiological hypoxia that activates genes that induce formation of the circulatory system (1). Thus a slight increase in oxidative glucose metabolism resulting from increased glucose delivery to the embryo may accelerate $\mathrm{O}_{2}$ utilization before establishment of the circulatory system can augment $\mathrm{O}_{2}$ delivery. This could lead to a state of hypoxia in excess of the physiological hypoxia that is part of normal development. Hypoxia can stimulate mitochondrial production of $\mathrm{O}_{2}^{-}$at complexes II and III $(9-11,38,43)$. Thus it is possible that oxidative stress in the embryo might be the result of, at least in part, hypoxiadependent superoxide production, as a consequence of $\mathrm{O}_{2}$ depletion from increased glucose oxidation.

In this study, we tested the hypothesis that maternal hyperglycemia increases the hypoxic state of the embryo, leading to inhibited Pax3 expression and increased NTD, and whether this was associated with increased oxidative stress.

\section{MATERIALS AND METHODS}

Induction of diabetes and transient hyperglycemia. A flow chart of animal procedures is shown in Fig. 1. Diabetes was induced in 5- to 6-wk-old female ICR mice (Taconic, Germantown, NY), as described previously (41), with $100 \mathrm{mg} / \mathrm{kg}$ STZ (Sigma, St. Louis, MO) dissolved in $10 \mathrm{mM}$ sodium citrate $(\mathrm{pH} \mathrm{4.5)}$ and treated with subcutaneously implanted insulin pellets (Linshin, Scarborough, Ontario). Blood glucose was monitored daily with a Glucometer Elite (Bayer, Mishawaka, IN). STZ-diabetic mice maintained euglycemia with insulin pellets before pregnancy but developed hyperglycemia beginning on day 4.5 of pregnancy, thereby exposing the embryo to hyperglycemia during the entire postimplantation period. Transient hyperglycemia was induced by subcutaneous injection of $12.5 \%$ glucose dissolved in PBS at approximately hourly intervals to maintain blood glucose $\geq 16.7 \mathrm{mmol} / \mathrm{l}$, as described previously (20).
Controls were injected in parallel with PBS. Oxidative stress was induced on day 7.5 with AA (Sigma Chemicals) dissolved in $25 \%$ ( $\mathrm{vol} / \mathrm{vol}$ ) propylene glycol and administered at $3 \mathrm{mg} / \mathrm{kg}$ body wt at noon on day 7.5, as described previously (12). Glutathione (GSH) ethyl ester (EE; Sigma Chemicals) dissolved in PBS was administered at $1 \mathrm{mmol} / \mathrm{kg}$, in three doses on day 7.5 as described (28). Vitamin E-treated animals received chow supplemented with $0.125 \%$ (wt/wt) $(+)$ - $\alpha$-tocopherol succinate, which increased dietary intake of vitamin E by 21-fold, beginning on day 0.5 of pregnancy as described (12). Mice were killed to recover embryos for assay of markers of oxidative stress on day 7.5, for assay of Pax3 expression on day 8.5, or to score NTD on day 10.5. All procedures performed using animals that are described herein were approved by the Institutional Animal Care and Use Committees of the Joslin Diabetes Center and the Marine Biological Laboratory.

Recording embryo $\mathrm{O}_{2}$ flux. Preparation of $\mathrm{O}_{2}$ microsensors and $\mathrm{O}_{2}$ flux measurement were performed as described previously (31, 33, 48, $49)$ and as diagramed in Fig. $2 A$. Briefly, the microsensor, fabricated from platinum wire inserted in a pulled glass capillary, was placed adjacent to the target tissue and then oscillated with a frequency of 0.3 $\mathrm{Hz}$ over a distance of $10 \mu \mathrm{m}$. One-third of the data, collected during the movement of the probe and during the period of settlement after the movement, was discarded automatically. Comparison of the current from the near pole and far pole allows a differential measurement directly proportional to flux while simultaneously removing the background signal.

Experiments were conducted in a Faraday box mounted on an air table, incorporating a Zeiss Axioskop upright microscope. Temperature was held at $37^{\circ} \mathrm{C}$. The motion controllers, temperature controller and amplifiers, as well as coordinating software (IonView) were products of the BioCurrents Research Center (Marine Biological Laboratory, Woods Hole, MA; www.mbl.edu/BioCurrents).

For recording $\mathrm{O}_{2}$ flux in embryos on day 7.5 of pregnancy, nondiabetic mice were injected with $12.5 \%$ glucose to induce hyperglycemia as described above and in Ref. 20. After $3 \mathrm{~h}$ of hyperglycemia, mice were killed, and decidua were immediately removed from uteri and dissected in $37^{\circ} \mathrm{C}$ PBS to expose yolk sac-enclosed embryos. The yolk sac was pierced over the head fold, and $\mathrm{O}_{2}$ flux was recorded adjacent to the cranial neuroepithelium (Fig. $2 B$ ). Oxygen tension in the medium was atmospheric, giving rise to a concentration of $210 \mu \mathrm{M}$.

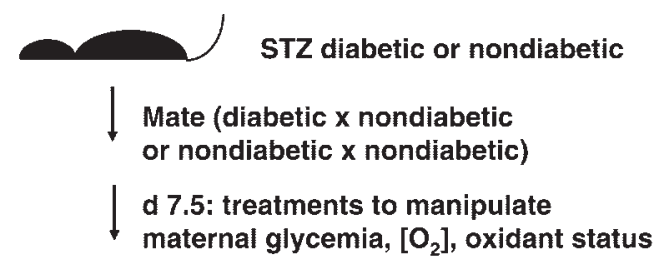

Sacrifice, assay embryos:

d $7.5+3 \mathrm{~h}$ :
$\mathrm{O}_{2}$ flux,
oxidative stress markers

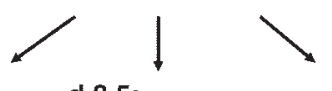

d 8.5:

Pax3 expression

d 10.5:

neural tube defects

Fig. 1. Flow diagram of animal procedures as described in MATERIALS AND METHODS. For animals to be made diabetic, diabetes was induced with streptozotocin (STZ) about 3 wk before mating. Nondiabetic mice were either controls for the diabetic mice or were used for manipulation of glycemia, oxygenation, and/or oxidant status in the absence of diabetes. Mice were mated along with age-matched controls, and noon of the day on which a copulation plug was found was determined to be day $(d) 0.5$. Mice were maintained on control breeder chow, except for mice in which the effects of vitamin E were tested, which were given chow supplemented with $0.125 \%$ vitamin E succinate. On day 7.5 , hyperglycemia was induced in some nondiabetic mice by subcutaneous glucose administration (controls were injected with saline); hypoxia was induced in nondiabetic mice by housing in a $12 \% \mathrm{O}_{2}$ chamber; hyperoxia was induced in diabetic and nondiabetic mice by housing in a $30 \% \mathrm{O}_{2}$ chamber; oxidative stress was induced in nondiabetic mice by administration of antimycin A; and the antioxidant glutathione (GSH) ethyl ester was administered to hyperglycemic, hypoxic, or saline-injected mice. Pregnant mice were killed for recovery of embryos at 1 of the following 3 time points: on day 7.5 after $3 \mathrm{~h}$ of hyperglycemia, hypoxia, or oxidative stress to assay $\mathrm{O}_{2}$ flux or markers of oxidative stress; on day 8.5 to assay Pax3 mRNA; or on day 10.5 to score neural tube defects (NTD). 
A

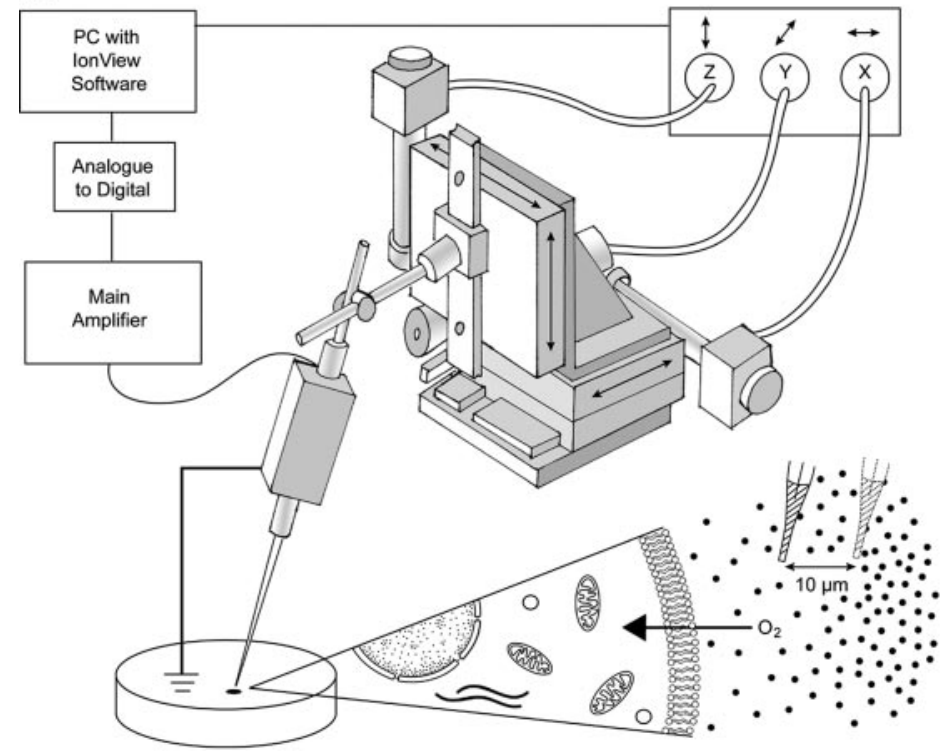

B

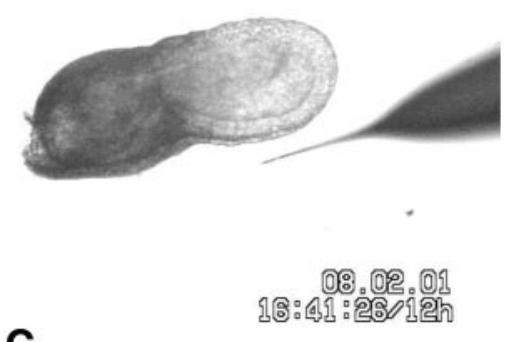

C

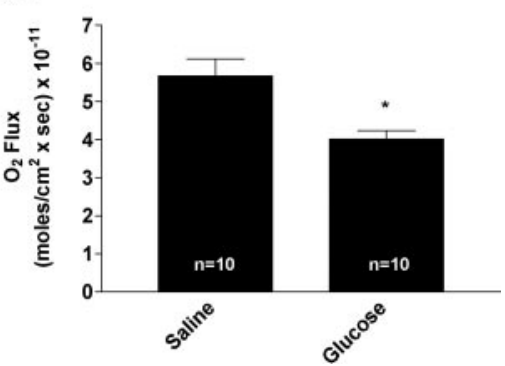

Fig. 2. A: diagram of $\mathrm{O}_{2}$ flux recording. The computer [personal computer (PC) with IonView software] serves the following 2 functions: to control electrode movement and to record $\mathrm{O}_{2}$ flux. Electrode movement is directed to cause the head stage to move the microelectrode back and forth within $10 \mu \mathrm{m}$ of the target tissue at a frequency of $0.3 \mathrm{~Hz}$. The current generated by the $\mathrm{O}_{2}$ gradient at the near pole (adjacent to the target tissue) and the far pole (10 $\mu \mathrm{m}$ from the target tissue) is transmitted through the main amplifier to the computer. $B$ : image of day 7.5 yolk sac-enclosed embryo next to microelectrode used to record $\mathrm{O}_{2}$ flux. $C: \mathrm{O}_{2}$ flux assayed in embryos of saline- or glucose-injected mice. ${ }^{*} P<0.005 ; n$, no. of embryos assayed.

Hypoxic and hyperoxic exposure. For induction of hypoxia and hyperoxia, pregnant mice were housed on day 7.5 in an OxyCycler chamber from Reming Bioinstruments (Redfield, NY), which is a semi-sealed, four-chamber Plexiglas incubator containing an $\mathrm{O}_{2}$ sensor and a small, quiet fan inside to provide forced circulation and instant homogenization of gases. It is attached to a computer for programmable adjustment of chamber $\mathrm{O}_{2}$ concentrations. To induce hypoxia, the chamber $\mathrm{O}_{2}$ concentration is reduced to $12 \%$ in $2 \%$ increments over a 15 -min period. To induce hyperoxia, the chamber $\mathrm{O}_{2}$ concentration was increased to $30 \%$ within a 5 -min period. Mice were exposed to hypoxia or hyperoxia for $3 \mathrm{~h}$ for experiments assaying markers of oxidative stress and $8 \mathrm{~h}$ for experiments assaying Pax3 mRNA or NTD.

Assay of malondialdehyde, $\mathrm{GSH}$, and $\mathrm{H}_{2} \mathrm{O}_{2}$. Embryos, including extraembryonic membranes, were recovered on day 7.5, and one-third of the embryos from each pregnancy was pooled and saved for assay of malondialdehyde (MDA), GSH, or $\mathrm{H}_{2} \mathrm{O}_{2}$. MDA was assayed spectrophotometrically, as described previously (15), using purified MDA (Sigma Chemicals) to generate a standard curve. GSH and $\mathrm{H}_{2} \mathrm{O}_{2}$ were assayed using kits obtained from Cayman Chemicals (Ann Arbor, MI) according to the manufacturer's instructions. The GSH kit measures total GSH and oxidized GSH (GSSG); GSH was determined from the difference between total GSH and GSSG. MDA, GSH, and $\mathrm{H}_{2} \mathrm{O}_{2}$ were normalized to protein concentrations in cell extracts, which were assayed using the Bio-Rad protein reagent (Bio-Rad, Hercules, CA).

Assay of Pax3 expression. Embryos from individual pregnancies were pooled, and RNA was prepared as described (40). Pax3 mRNA in each pregnancy was quantitated relative to one arbitrarily selected saline or nondiabetic/20\% $\mathrm{O}_{2}$ pregnancy, after normalization to rRNA, using real-time RT-PCR, as described previously (12).

Statistical analyses. Data were analyzed from a minimum of three pregnancies per treatment group by one-way ANOVA, followed by the Neuman-Keuls post hoc test, using GraphPad Prism software (San Diego, CA).

\section{RESULTS}

Maternal hyperglycemia suppresses aerobic respiration. Aerobic respiration depends on $\mathrm{O}_{2}$ delivery. Thus, although glucose metabolism in the day 7.5 mouse embryo is predominantly anaerobic (2), we hypothesized that an increase in glucose delivery to the embryo resulting from maternal hyperglycemia would transiently increase aerobic metabolism. Thus, if $\mathrm{O}_{2}$ were consumed faster than it can be replenished, this would suppress aerobic metabolism by the embryo, leading to decreased $\mathrm{O}_{2}$ flux. To test this, we assayed $\mathrm{O}_{2}$ flux, which is an indicator of aerobic metabolism, in day 7.5 embryos after $3 \mathrm{~h}$ of maternal hyperglycemia $(\geq 16.7 \mathrm{mmol} / \mathrm{l})$ using self-referencing $\mathrm{O}_{2}$ microelectrodes (Fig. 2A). An image of a microelectrode next to a yolk sac-enclosed embryo is shown in Fig. $2 B$. As shown in Fig. 2C, $\mathrm{O}_{2}$ flux was reduced significantly in embryos of hyperglycemic mice. This indicates that, consistent with the hypothesis, after $3 \mathrm{~h}$ of maternal hyperglycemia, aerobic respiration was suppressed, suggesting that a state of hypoxia in excess of that of normal day 7.5 embryos was induced.

Maternal hypoxia replicates, and hyperoxia suppresses, the effects of maternal diabetes on Pax3 expression and NTD. If hyperglycemia inhibits $\operatorname{Pax} 3$ expression and increases NTD by inducing hypoxic stress in the embryo, then reducing $\mathrm{O}_{2}$ delivery to embryos should replicate the effects of maternal hyperglycemia, and increasing $\mathrm{O}_{2}$ delivery should block the effects of maternal diabetes.

To test whether reducing $\mathrm{O}_{2}$ delivery to embryos replicates the adverse effects of hyperglycemia, pregnant mice were housed in a programmable $\mathrm{O}_{2}$ chamber, ramping down from room air $\left(20 \% \mathrm{O}_{2}\right)$ to $12 \% \mathrm{O}_{2}$ on day 7.5 . Mice were made hyperglycemic by glucose injection or injected with saline as 
Table 1. Mean blood glucose levels of pregnancies in Fig. 3, $A$ and $B$

\begin{tabular}{cccc}
\hline \hline & Saline & Glucose & Hypoxia \\
\hline Day 7.5 blood glucose, mM & $7.0 \pm 0.08$ & $19.3 \pm 0.46^{*}$ & $7.1 \pm 0.13$ \\
\hline
\end{tabular}

Values are means \pm SE. $* P<0.001$ vs. saline and hypoxia.

controls. Table 1 shows that there was no effect of maternal hypoxia on blood glucose concentrations, whereas glucose injection significantly increased maternal blood glucose concentrations. Nevertheless, maternal hypoxia, like maternal hyperglycemia, significantly inhibited Pax3 expression and increased NTD (Fig. 3, $A$ and $B$ ).

To test whether increasing $\mathrm{O}_{2}$ delivery blocks the adverse effects of maternal diabetes, diabetic or nondiabetic mice were housed at $30 \% \mathrm{O}_{2}$ on day 7.5 of pregnancy. Control diabetic and nondiabetic mice were kept in room air $\left(20 \% \mathrm{O}_{2}\right)$. As shown in Table 2, hyperoxia had no effect on maternal blood glucose concentrations, which were significantly elevated in diabetic mice. Nevertheless, although hyperoxia had no effect on Pax3 expression and NTD in embryos of nondiabetic mice, it blocked the inhibition of Pax3 expression and NTD in embryos of diabetic mice (Fig. 3, $C$ and $D$ ).

Hypoxic stress induces oxidative stress in embryos. We have previously shown that oxidative stress, induced by maternal hyperglycemia or the mitochondrial complex III inhibitor, AA, inhibits Pax3 expression and induces NTD (12). Noting that hypoxic stress can stimulate superoxide production $(9-11,38$, 43), we hypothesized that the adverse effects of hyperglycemia-induced hypoxic stress on Pax3 expression and NTD could be mediated, at least in part, by oxidative stress. To test this hypothesis, we assayed markers of oxidative stress (MDA and $\mathrm{GSH}$, as well as $\mathrm{H}_{2} \mathrm{O}_{2}$, the production of which is increased upon increased superoxide production) after $3 \mathrm{~h}$ of maternal exposure to $12 \% \mathrm{O}_{2}$. As shown in Fig. 4A, MDA, a
Table 2. Mean blood glucose levels of pregnancies in Fig. 3, $C$ and D

\begin{tabular}{ccccc}
\hline \hline & ND/Normoxia & ND/Hyperoxia & D/Normoxia & D/Hyperoxia \\
\hline $\begin{array}{c}\text { Day 7.5 blood } \\
\text { glucose, } \mathrm{mM}\end{array}$ & $7.2 \pm 0.084$ & $7.1 \pm 0.131$ & $30.1 \pm 0.833 *$ & $29.6 \pm 1.060 *$ \\
\hline
\end{tabular}

Values are means \pm SE. ND, nondiabetic; $\mathrm{D}$, diabetic. $* P<0.001$ vs. ND.

marker of lipid peroxidation, was significantly increased by maternal hypoxia to the same extent that it was increased by hyperglycemia or AA. Another indicator of oxidative stress, GSH, was significantly decreased by hypoxia to the same extent that it was decreased by hyperglycemia or AA (Fig. 4B). $\mathrm{H}_{2} \mathrm{O}_{2}$ was increased equally by hypoxia, hyperglycemia, and AA (Fig. $4 C$ ).

Conversely, we tested whether increasing $\mathrm{O}_{2}$ delivery to embryos blocks oxidative stress induced by maternal diabetes. There was no effect of hyperoxia $\left(30 \% \mathrm{O}_{2}\right)$ on MDA in nondiabetic pregnancies, but the increase in MDA observed in diabetic pregnancies was significantly reduced by hyperoxia, although it was still significantly increased over MDA in nondiabetic pregnancies exposed to either normoxia or hyperoxia (Fig.4D). Similarly, there was no effect of hyperoxia on GSH, but the decrease in GSH induced by maternal diabetes was significantly reduced by hyperoxia, although GSH was still significantly reduced in embryos of diabetic mice exposed to hyperoxia compared with embryos of nondiabetic mice exposed to either normoxia or hyperoxia (Fig. 4E). The increase in $\mathrm{H}_{2} \mathrm{O}_{2}$ observed in diabetic pregnancies was significantly suppressed by hyperoxia, although it remained significantly increased compared with nondiabetic pregnancies exposed to either normoxia or hyperoxia (Fig. $4 F$ ).

Antioxidant administration blocks the adverse effects of embryo hypoxia on neural tube development. To further test the hypothesis that hypoxic stress induces oxidative stress,
Fig. 3. Effects of hypoxia or hyperoxia on Pax3 expression and NTD. $A$ and $B$ : pregnant mice were housed at $12 \% \mathrm{O}_{2}$ on day 7.5 of pregnancy or injected with glucose to induce hyperglycemia or saline as a control, as described in MATERIALS AND METHODS. $C$ and $D$ : pregnant diabetic (D) or nondiabetic (ND) mice were housed in room air $\left(\sim 20 \% \mathrm{O}_{2}\right.$, normoxia) or at $30 \% \mathrm{O}_{2}$ on day 7.5, as described in MATERIALS AND METHODS. Embryos were recovered on day 8.5 to assay relative Pax3 expression by RT-PCR ( $A$ and $C$ ), or on day 10.5 to score NTD $(B$ and $D) . A: * P<0.01$ vs. saline. $B$ : $* P<0.0005$ vs. saline. $C$ : $* P<0.001$ vs. all other treatment groups. $D: * P<0.01$ vs. all other treatment groups; $n$, no. of pregnancies assayed.
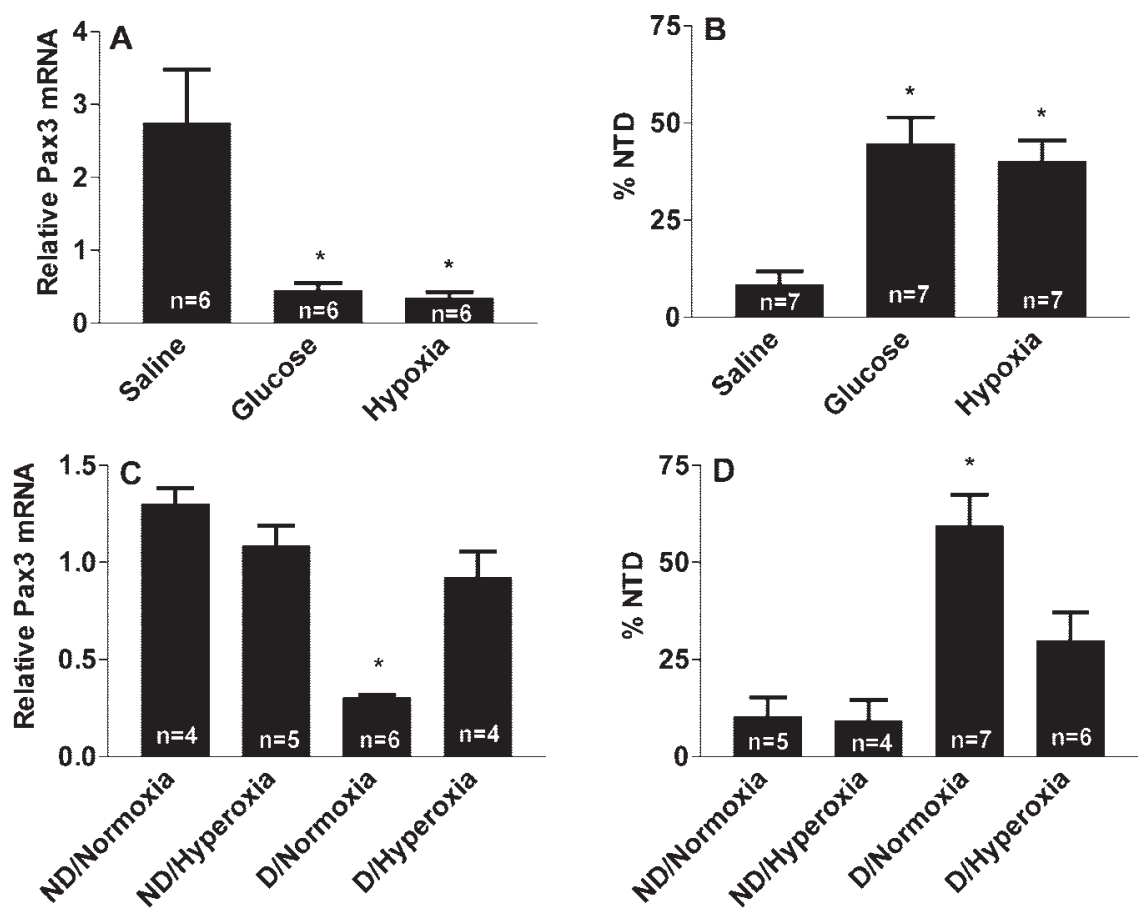
A
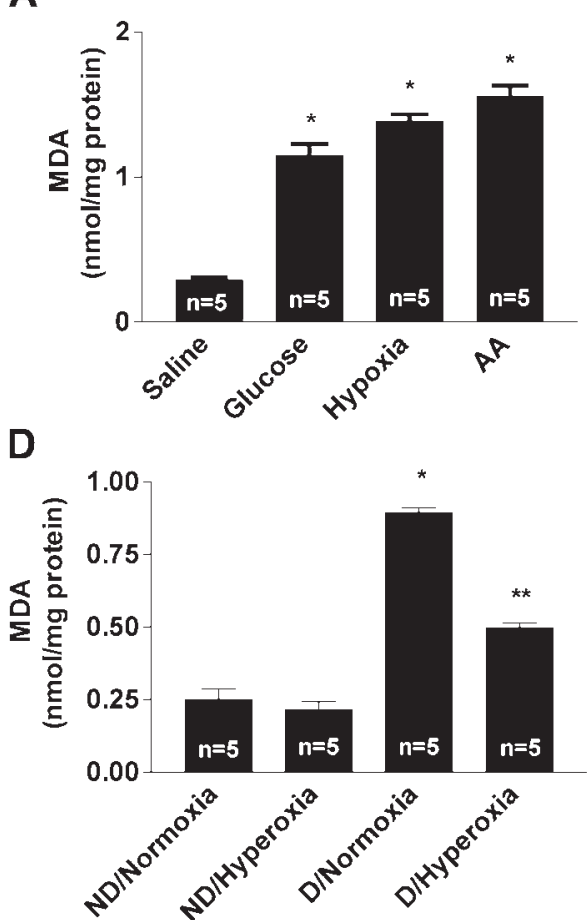

B

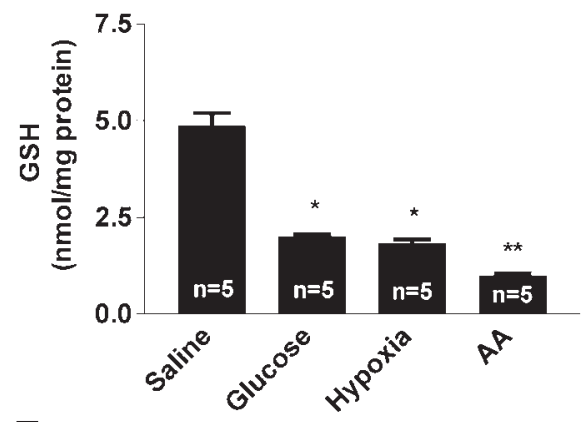

$\mathbf{E}$

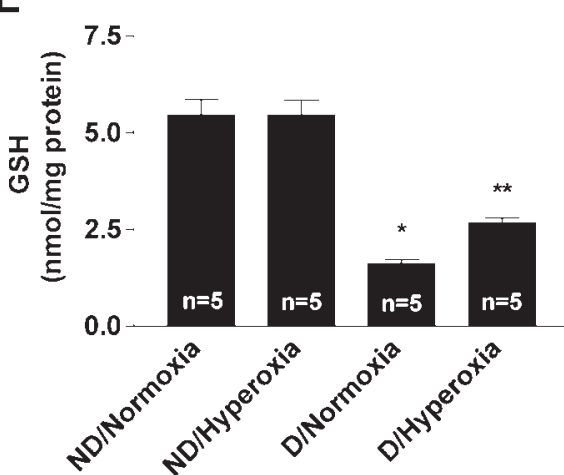

C

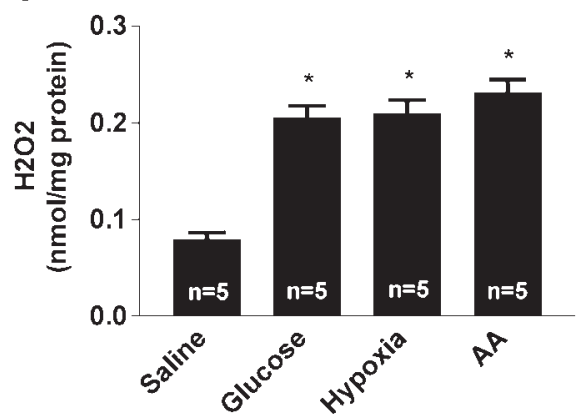

$\mathbf{F}$

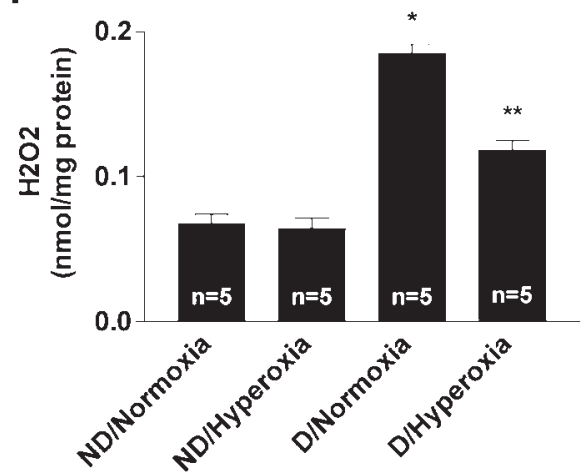

Fig. 4. Malondialdehyde (MDA), reduced GSH, and $\mathrm{H}_{2} \mathrm{O}_{2}$ in pregnancies treated as in Fig. 3. Antimycin A (AA) was administered as a control for stimulation of $\mathrm{H}_{2} \mathrm{O}_{2}$ production. $A$ : $* P<0.001$ vs. saline. $B$ : $* P<0.001$ vs. saline; $* * P<0.001$ vs. saline, glucose, and hypoxia. $C$ : $* P<0.001$ vs. saline. $D$ : $* P<0.001$ vs. ND (normoxia and hyperoxia); $* * P<0.001$ vs. all other treatment groups. $E$ : $* P<0.001$ vs. ND (normoxia and hyperoxia); $* * P<0.001$ vs. all other treatment groups. $F: * P<0.001$ vs. ND (normoxia and hyperoxia); $* * P<0.001$ vs. all other treatment groups.

which thereby mediates the adverse effects of maternal hyperglycemia, the membrane-soluble GSH analog GSH-EE was administered on day 7.5 to mice that were housed at $12 \% \mathrm{O}_{2}$, or to glucose- or saline-injected mice as controls. Noting that opening chamber door had the potential to restore normoxia during the three times that GSH-EE was administered to animals housed in the $\mathrm{O}_{2}$ chamber, the effect of opening the door without GSH-EE administration was also tested as a control.

As shown in Table 3, only glucose-injected mice were hyperglycemic, and GSH-EE had no effect on glycemia in any treatment group. In contrast, the inhibition of Pax3 expression induced by hypoxia or hyperglycemia was prevented by coincident administration of GSH-EE (Fig. 5A). This effect could not be attributed to transient normoxia during the time the OxyCycler chamber doors were opened to administer GSHEE, since Pax3 expression was still reduced in embryos of mice exposed to hypoxia during day 7.5 when the chamber doors were opened for times comparable for injection of GSH-EE. Correspondingly, the increase in NTD induced by hypoxia or hyperglycemia was prevented by GSH-EE, and this cannot be explained by transient normoxia during administration of GSH-EE (Fig. 5B).
To further test whether the adverse effects of hyperglycemia-induced hypoxia are the result of oxidative stress, the effects of another antioxidant were tested. Vitamin E succinate, which we previously showed prevented the adverse effects of maternal diabetes on Pax3 expression and NTD (12), was administered by dietary supplementation beginning on day 0.5 of pregnancy. As shown in Fig. 5, $C$ and $D$, supplemental vitamin E prevented the inhibition in Pax3 expression and the increase in NTD induced by hypoxia and hyperglycemia but had no effect on glycemia (Table 4).

\section{DISCUSSION}

There is much evidence implicating oxidative stress in the pathogenesis of diabetic embryopathy $(12,18,19,25,42,46$, 47, 54). More recently, we have shown that oxidative stress causes diabetic pregnancy-induced NTD because it disrupts expression of at least one gene (Pax3), which is crucial for neural tube development (12). However, the possibility that maternal hyperglycemia could cause excessive hypoxia in the embryo, and that this could be a source of oxidative stress, has not been reported previously.

Table 3. Mean blood glucose levels of pregnancies in Fig. 5, A and B

\begin{tabular}{cccccccc}
\hline \hline & Saline & Glucose & Hypoxia & Saline + GSH & Glucose + GSH & Hypoxia + GSH & Hypoxia + Open Door \\
\hline Day 7.5 blood glucose, $\mathrm{mM}$ & $7.4 \pm 0.09$ & $18.6 \pm 0.35^{*}$ & $7.6 \pm 0.17$ & $7.6 \pm 0.12$ & $18.4 \pm 0.28^{*}$ & $7.1 \pm 0.11$ & $7.5 \pm 0.17$ \\
\hline
\end{tabular}

Values are means $\pm \mathrm{SE}$. GSH, glutathione. ${ }^{*} P<0.001$ vs. all saline and hypoxia groups. 
Fig. 5. Effects of GSH ethyl ester (EE) or vitamin (vit) E succinate on Pax3 expression or NTD induced by maternal hypoxia. Pregnant mice were housed at $12 \%$ $\mathrm{O}_{2}$ or made hyperglycemic by glucose injection on day 7.5 as in Fig. 3, $A$ and $B$. Controls were injected with saline. GSH-EE was administered 3 times during day $7.5(A$ and $B)$, or pregnant dams were fed control chow or chow supplemented with vitamin $\mathrm{E}$ succinate from day $0.5(C$ and $D)$. As a control for transient normoxia while administering GSH to animals housed at $12 \% \mathrm{O}_{2}$, the OxyCycler chamber door was left open for some hypoxia-exposed dams for the same duration as required to administer GSH (Hypoxia + open door). $A$ : $* P<0.001$ vs. saline, saline $+\mathrm{GSH}$, glucose $+\mathrm{GSH}$, or hypoxia + GSH. $B$ : $* P<0.001$ vs. saline, saline + GSH, glucose $+\mathrm{GSH}$, or hypoxia + GSH. $C: * P<$ 0.001 vs. saline and saline + vit $\mathrm{E}, P<0.01$ vs. glucose + vit $\mathrm{E} ; * * P<0.001$ vs. saline and saline + vit E, $P<0.01$ vs. hypoxia + vit E. $D$ : ${ }^{*} P<0.001$ vs. saline, saline + vit E, glucose + vit E, and hypoxia + vit $\mathrm{E}$.
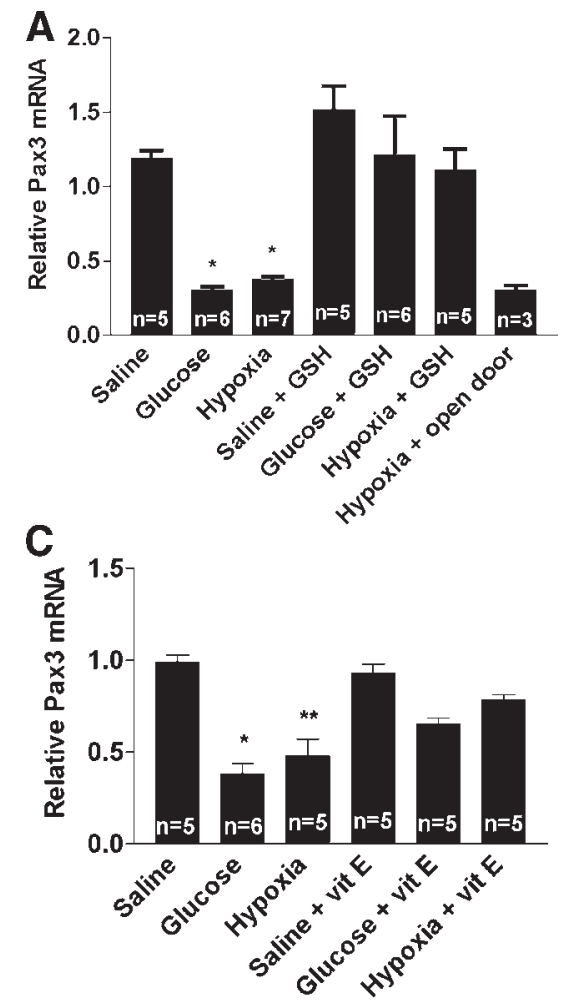
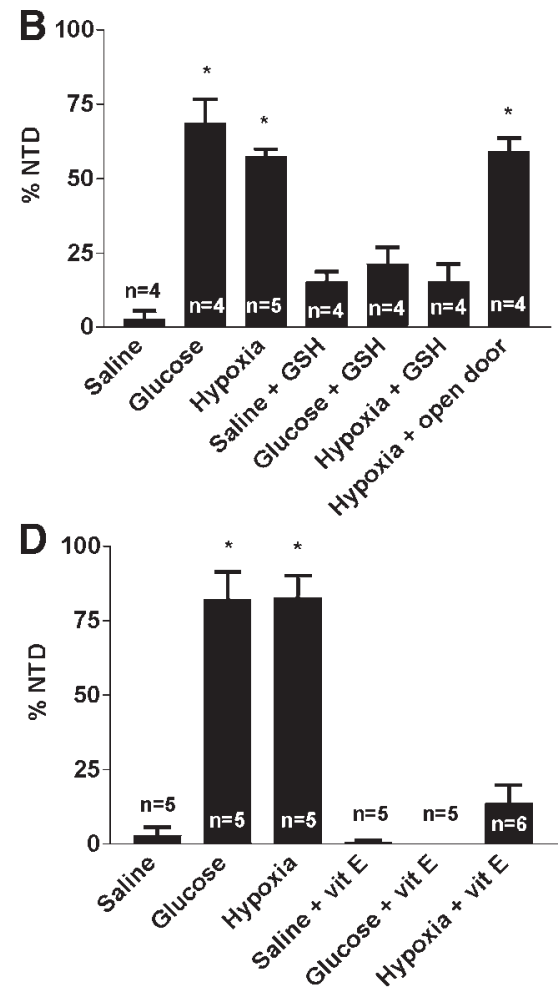

Physiological hypoxia, caused by the increasing mass of the avascular early postimplantation embryo, plays a critical role during normal embryogenesis. As the embryo, which is already located in a relatively hypoxic environment $(21,44)$, increases in mass, $\mathrm{O}_{2}$ delivery becomes increasingly diffusion limited. This physiological hypoxia activates the Hif-1 $\alpha /$ ARNT heterodimeric transcription factor to induce expression of genes that trigger formation of blood islands in the yolk sac $(1,22$, 30 ). The primitive circulatory system of the embryo proper is also dependent on hypoxia-responsive transcription, since embryos lacking EPAS-1, which is hypoxia inducible, fail to develop a normal heart and circulatory system (50). Thus, in response to normal growth of the embryo, diffusion-limited $\mathrm{O}_{2}$ delivery induces physiological hypoxia, and this activates expression of genes whose products induce hematopoiesis and structures forming the circulatory system, thereby increasing $\mathrm{O}_{2}$ delivery to embryonic tissues and reducing the hypoxic state.

Increased $\mathrm{O}_{2}$ delivery may be critical for the development of organ systems in which primordia appear just after this hypoxia-responsive period, such as the neural tube, because embryos that lack Hif-1 $\alpha, A R N T, V E G F$, or sufficient gene copy numbers of $p 300$ and/or $C B P$, which encode coactivators of Hif-1 $\alpha$ /ARNT-dependent transcription, develop NTD (6, $32,34,50,57)$. Thus failure to increase $\mathrm{O}_{2}$ delivery at this stage of development may impair activation of genes needed for formation of the neural tube. Conversely, increased $\mathrm{O}_{2}$ delivery may be a developmental signal of metabolic fitness to support further development, which induces expression of certain genes that control critical developmental programs.

In the rat embryo, only $1.2 \%$ of glucose is metabolized oxidatively on day 10 (corresponding to approximately day 8 in the mouse), but it increases to $8.3 \%$ on day 11 (2). The increase in aerobic metabolism is made possible by increased $\mathrm{O}_{2}$ delivery from establishment of the primitive yolk sac circulation. This period of development coincides with the stage of development that is sensitive to maternal hyperglycemia (20). As shown here, $3 \mathrm{~h}$ of maternal hyperglycemia on day 7.5 decreases $\mathrm{O}_{2}$ flux. This suggests that increased glucose metabolism, which acutely increases $\mathrm{O}_{2}$ consumption, leads to relative $\mathrm{O}_{2}$ depletion, thereby inhibiting oxidative metabolism and suppressing $\mathrm{O}_{2}$ flux. It is also possible that decreased $\mathrm{O}_{2}$ flux could be the result of mitochondrial damage. Indeed, it has been suggested that exposure of rat embryo or fetal neural tissues to $50 \mathrm{mM}$ glucose or maternal diabetes can suppress oxidative metabolism, perhaps because of the Crabtree effect, in which increased glucose metabolism leads to diminished supply of ADP, which, by inducing state 4 respiration, increases the production of superoxide $(8,14,56)$. Another possibility is that hyperglycemia-induced increased ratio of $\mathrm{NADH}$ to $\mathrm{NAD}^{+}$could cause a "pseudohypoxic" state, despite normal $\mathrm{O}_{2}$ tension, which has been postulated to be associated

Table 4. Mean blood glucose levels of pregnancies in Fig. 5, C and D

\begin{tabular}{ccccccc}
\hline \hline & Saline & Glucose & Hypoxia & Saline + Vit E & Glucose + Vit E & Hypoxia + Vit E \\
\hline Day 7.5 blood glucose, $\mathrm{mM}$ & $7.2 \pm 0.07$ & $18.9 \pm 0.4^{*}$ & $7.1 \pm 0.13$ & $7.3 \pm 0.05$ & $19.8 \pm 0.26^{*}$ & $7.4 \pm 0.19$ \\
\hline
\end{tabular}

Values are means \pm SE. Vit, vitamin. $* P<0.001$ vs. all saline and hypoxia groups. 


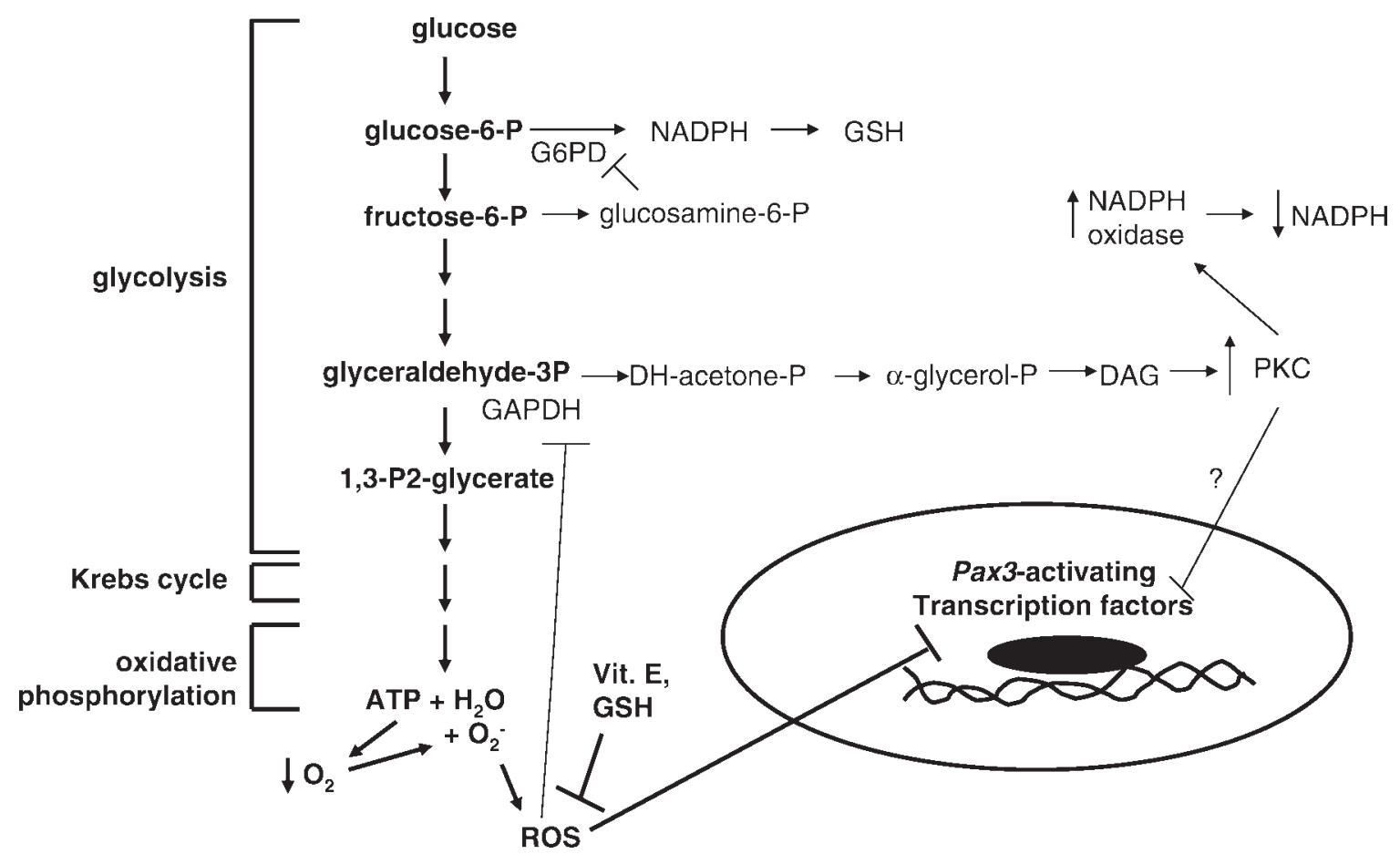

Fig. 6. Flow diagram of pathways affected by excess glucose in the embryo leading to impaired Pax3 expression. During diabetic pregnancy, increased glucose transport from maternal circulation increases glucose metabolism by the embryo. Increased oxidative metabolism increases $\mathrm{O}_{2}$ consumption; however, because $\mathrm{O}_{2}$ cannot be replaced as quickly as it is consumed, this will lead to decreased $\mathrm{O}_{2}$ availability. Excessive hypoxia increases superoxide and $\mathrm{H}_{2} \mathrm{O}_{2}$ production, thereby increasing reactive oxygen species (ROS), which inhibit Pax3 expression by a yet unidentified mechanism. The effects of oxidative stress can be blocked by GSH precursors and vitamin E. Other studies have shown that oxidative stress inhibits GAPDH activity and that accumulation of glycolytic intermediates stimulate the diacylglycerol (DAG)/protein kinase C (PKC) and hexosamine flux pathways. Activation of PKC activity can stimulate NADPH oxidase activity, leading to decreased production of reduced GSH (although whether PKC regulates Pax3 expression is not known). Activation of the hexosamine flux pathway inhibits the pentose shunt pathway, thereby decreasing NADPH and reduced GSH production. P, phosphate; G6PD, glucose-6-phosphate dehydrogenase; DH, dihydroxy; $\mathrm{P}_{2}$, biphospho.

with diabetic vascular complications (55). Although our results are not inconsistent with either a Crabtree or pseudo-hypoxic effect, the fact that the adverse effects of maternal diabetes could be prevented by transient hyperoxia would suggest that they are not the result of irreversible mitochondrial damage and that limiting availability of $\mathrm{O}_{2}$ mediates some of the adverse effects of maternal hyperglycemia. Thus our findings suggest that excess glucose stimulates mitochondrial $\mathrm{O}_{2}$ utilization, leading to a state of hypoxia in excess of that of the normal day 7.5 embryo.

The data reported here support the hypothesis that hyperglycemia-induced $\mathrm{O}_{2}$ depletion contributes to the adverse effects of maternal diabetes on the embryo. Specifically, when $\mathrm{O}_{2}$ depletion was experimentally induced by restricting $\mathrm{O}_{2}$ delivery to pregnant mice on day 7.5, all of the responses induced by maternal hyperglycemia (decreased Pax3 expression, increased NTD and markers of oxidative stress) were observed. Conversely, when increased $\mathrm{O}_{2}$ consumption induced by maternal diabetes was experimentally compensated by increasing $\mathrm{O}_{2}$ delivery to pregnant diabetic mice on day 7.5 , all of the responses of maternal diabetes were diminished. This suggests that excessive embryo hypoxia caused by increased glucose metabolism suppresses the increase in $\mathrm{O}_{2}$ availability that would normally occur at this stage of development. Consequently, the processes leading to induction of $P a x 3$, which may depend on increased $\mathrm{O}_{2}$ delivery, are impaired. A further implication of these findings is that if, during normal develop- ment, induction of the blood or circulatory systems in response to physiological hypoxia fails, for example, because of deficient activation of Hif-1 $\alpha$ - or Epas-1-dependent transcription, oxidative stress, leading to insufficient expression of Pax3, would result. This could explain the NTD that arise in such animal models.

In considering mechanisms by which glucose-induced excess hypoxic stress might inhibit Pax3 expression and increase NTD, we considered several mechanisms, including activation of Hif-1a-dependent transcription $(39,45)$ or stimulation of AMP kinase activity $(27,35)$. These pathways notwithstanding, noting that hyperglycemia-induced oxidative stress inhibits Pax3 expression (12) and that hypoxia has the potential to increase superoxide production $(9-11,38,43)$, we tested whether oxidant status was increased by hypoxia. Remarkably, all measures of oxidative stress (MDA, GSH, and $\mathrm{H}_{2} \mathrm{O}_{2}$ ) were equally affected by hypoxia and by hyperglycemia, and these markers of oxidative stress were equivalently attenuated by hyperoxia in embryos of diabetic mice.

Additional evidence that the adverse effects of glucoseinduced hypoxic stress are mediated by oxidative stress was that the adverse effects of hypoxia were prevented by GSH-EE. Because GSH could have effects independent of its antioxidant properties, we tested another antioxidant, vitamin $\mathrm{E}$, which we previously showed to inhibit the adverse effects of maternal diabetes on Pax3 expression and NTD (12). Like GSH-EE, vitamin $\mathrm{E}$ also prevented the decrease in Pax3 expression and 
the increase in NTD induced by hypoxia or by hyperglycemia, suggesting that the adverse effects of hyperglycemia, leading to hypoxic stress, are mediated by superoxide-generated oxidative stress.

It is interesting to note that hyperoxia did not increase markers of oxidant status or inhibit $\operatorname{Pax} 3$ expression in nondiabetic pregnancies. This suggests that, at this stage of development, maternal exposure to $30 \% \quad \mathrm{O}_{2}$ does not increase superoxide production if glucose delivery to the embryo does not also increase. In diabetic pregnancies, markers of oxidative stress were significantly improved by hyperoxia. Even though oxidant status was not completely normalized in diabetic pregnancies by hyperoxia, it was apparently corrected sufficiently to prevent inhibition of Pax3 expression.

The multiple biochemical pathways affected by high glucose are complex (Fig. 6). For example, we have shown that the diacylglycerol (DAG)/protein kinase $\mathrm{C}$ (PKC) pathway is activated in embryos of diabetic or hyperglycemic mice (26), which could contribute to oxidative stress by activation of NADPH oxidase activity (29), and that stimulation of the hexosamine flux pathway by hyperglycemia causes oxidative stress and inhibits Pax3 expression through depletion of GSH (28). These effects may actually be secondary to hypoxiainduced superoxide production. Du et al. (16) have shown that increased mitochondrial superoxide production inhibits glyceraldehyde-3-PO ${ }_{4}$ dehydrogenase (GAPDH) activity, which causes glycolytic intermediates to accumulate. The glycolytic intermediates, glyceraldehyde-3- $\mathrm{PO}_{4}$ and fructose-6- $\mathrm{PO}_{4}$, stimulate synthesis of DAG and glucosamine-6- $\mathrm{PO}_{4}$, respectively (5, 16). In support of this model in diabetic pregnancy, inhibition of GAPDH has been observed in rat embryos exposed to a hyperglycemic environment (53). Thus the data presented here, in which maternal hyperglycemia of $\sim 19 \mathrm{mmol} / 1$, or $12 \% \mathrm{O}_{2}$, caused the same quantitative changes in markers of oxidant status, Pax3 expression, and NTD, suggest that many of the effects of hyperglycemia result from $\mathrm{O}_{2}$ depletion-induced oxidative stress. Further research will be necessary to determine whether the activation of PKC and hexosamine pathways is solely the result of increased mitochondrial superoxide production and inhibition of GAPDH activity and exactly how oxidative stress leads to inhibition of Pax3 expression.

\section{ACKNOWLEDGMENTS}

We are grateful to Melissa Horal and Julie Adams for technical support, Allen Clermont and George King for use of the OxyCycler, and Tamara Clark for graphic art.

Current addresses: M. Chase, UCSF Mission Bay, 600 16th St., Genentech Hall N276, Box 2140, San Francisco, CA 94143; and S.-K. Jung, Bayer HealthCare, LLC, 1111 Bristol St., Elkhart, IN 46514.

\section{GRANTS}

This work was supported by National Institutes of Health Grant RO1 DK-58300 to M. R. Loeken and P41 RR-001395 to P. J. S. Smith.

\section{REFERENCES}

1. Adelman DM, Maltepe E, and Simon MC. Multilineage embryonic hematopoiesis requires hypoxic ARNT activity. Genes Dev 13: $2478-$ 2483, 1999.

2. Akazawa S, Unterman T, and Metzger BE. Glucose metabolism in separated embryos and investing membranes during organogenesis in the rat. Metabolism 43: 830-835, 1994.

3. Auerbach R. Analysis of the developmental effects of a lethal mutation in the house mouse. J Exp Zool 127: 305-329, 1954.
4. Becerra JE, Khoury MJ, Cordero JF, and Erickson JD. Diabetes mellitus during pregnancy and the risks for the specific birth defects: A population-based case-control study. Pediatrics 85: 1-9, 1990.

5. Brownlee M. Biochemistry and molecular cell biology of diabetic complications. Nature 414: 813-820, 2001.

6. Carmeliet P, Ferreira V, Breier G, Pollefeyt S, Kieckens L, Gertsenstein M, Fahrig M, Vandenhoeck A, Harpal K, Eberhardt C, Declercq C, Pawling J, Moons L, Collen D, Risau W, and Nagy A. Abnormal blood vessel development and lethality in embryos lacking a single VEGF allele. Nature 380: 435-439, 1996.

7. Chalepakis G, Goulding M, Read A, Strachan T, and Gruss P. Molecular basis of splotch and Waardenburg Pax-3 mutations. Proc Natl Acad Sci USA 91: 3685-3689, 1994.

8. Chance B and Hess B. Metabolic control mechanisms. IV. The effect of glucose upon the steady state of respiratory enzymes in the ascites cell. J Biol Chem 234: 2421-2427, 1959.

9. Chandel NS, Maltepe E, Goldwasser E, Mathieu CE, Simon MC, and Schumacker PT. Mitochondrial reactive oxygen species trigger hypoxiainduced transcription. Proc Natl Acad Sci USA 95: 11715-11720, 1998.

10. Chandel NS, McClintock DS, Feliciano CE, Wood TM, Melendez JA, Rodriguez AM, and Schumacker PT. Reactive oxygen species generated at mitochondrial complex III stabilize hypoxia-inducible factor1alpha during hypoxia: a mechanism of $\mathrm{O} 2$ sensing. J Biol Chem 275: 25130-25138, 2000.

11. Chandel NS, Vander Heiden MG, Thompson CB, and Schumacker PT. Redox regulation of p53 during hypoxia. Oncogene 19: 3840-3848, 2000.

12. Chang TI, Horal M, Jain S, Wang F, Patel R, and Loeken MR. Oxidant regulation of gene expression and neural tube development: Insights gained from diabetic pregnancy on molecular causes of neural tube defects. Diabetologia 46: 538-545, 2003.

13. Conway SJ, Henderson DJ, and Copp AJ. Pax3 is required for cardiac neural crest migration in the mouse: evidence from the splotch $(\mathrm{Sp} 2 \mathrm{H})$ mutant. Development 124: 505-514, 1997.

14. Crabtree HG. Observations on the carbohydrate metabolism of tumours. Biochem J 23: 536-545, 1929.

15. Draper HH and Hardley M. Malondialdehype determination as an index of lipid peroxidation. In: Methods in Enzymology, edited by Packer L and Glazer AN. New York: Academic, 1990, p. 421-431.

16. Du XL, Edelstein D, Rossetti L, Fantus IG, Goldberg H, Ziyadeh F, Wu J, and Brownlee M. Hyperglycemia-induced mitochondrial superoxide overproduction activates the hexosamine pathway and induces plasminogen activator inhibitor-1 expression by increasing Sp1 glycosylation. Proc Natl Acad Sci USA 97: 12222-12226, 2000.

17. Epstein DJ, Vogan KJ, Trasler DG, and Gros P. A mutation within intron 3 of the Pax-3 gene produces aberrantly spliced mRNA transcripts in the splotch (Sp) mouse mutant. Proc Natl Acad Sci USA 90: 532-536, 1993.

18. Eriksson U and Siman CM. Pregnant diabetic rats fed the antioxidant butylated hydroxytoluene show decreased occurrence of malformations in offspring. Diabetes 45: 1497-1502, 1996.

19. Eriksson UJ and Borg LAH. Protection by free oxygen radical scavenging enzymes against glucose-induced embryonic malformations in vitro. Diabetologia 34: 325-331, 1991.

20. Fine E, Horal M, Chang T, Fortin G, and Loeken M. Hyperglycemia is responsible for altered gene expression, apoptosis, and neural tube defects associated with diabetic pregnancy. Diabetes 48: 2454-2462, 1999.

21. Fischer B and Bavister BD. Oxygen tension in the oviduct and uterus of rhesus monkeys, hamsters and rabbits. J Reprod Fertil 99: 673-679, 1993.

22. Forsythe JA, Jiang BH, Iyer NV, Agani F, Leung SW, Koos RD, and Semenza GL. Activation of vascular endothelial growth factor gene transcription by hypoxia-inducible factor 1. Mol Cell Biol 16: 4604-4613, 1996.

23. Goulding M, Sterrer S, Fleming J, Balling R, Nadeau J, Moore KJ, Brown SDM, Steel KP, and Gruss P. Analysis of the Pax-3 gene in the mouse mutant splotch. Genomics 17: 355-363, 1993.

24. Goulding MD, Chalepakis G, Deutsch U, Erselius JR, and Gruss P. Pax-3, a novel murine DNA binding protein expressed during early neurogenesis. EMBO J 10: 1135-1147, 1991.

25. Hagay ZJ, Weiss Y, Zusman I, Peled-Kamar M, Reece EA, Eriksson UJ, and Groner Y. Prevention of diabetes-associated embryopathy by overexpression of the free radical scavenger copper zinc superoxide 
dismutase in transgenic mouse embryos. Am J Obstet Gynecol 173: 1036-1041, 1995.

26. Hiramatsu Y, Sekiguchi N, Hayashi M, Isshiki K, Yokota T, King G, and Loeken MR. Diacylglycerol production and protein kinase C activity are increased in a mouse model of diabetic embryopathy. Diabetes 51: 2804-2810, 2002

27. Hong YH, Varanasi US, Yang W, and Leff T. AMP-activated protein kinase regulates HNF4alpha transcriptional activity by inhibiting dimer formation and decreasing protein stability. J Biol Chem 278: 27495 27501, 2003

28. Horal M, Zhang Z, Virkamaki A, Stanton R, and Loeken MR. Activation of the hexosamine pathway causes oxidative stress and abnormal embryo gene expression: Involvement in diabetic teratogenesis. Birth Defects Res Part A Clin Mol Teratol 70: 519-527, 2004.

29. Hua H, Munk S, Goldberg H, Fantus IG, and Whiteside CI. High glucose-suppressed endothelin-1 $\mathrm{Ca} 2+$ signaling via NADPH oxidase and diacylglycerol-sensitive protein kinase $\mathrm{C}$ isozymes in mesangial cells. J Biol Chem 278: 33951-33962, 2003.

30. Iyer NV, Kotch LE, Agani F, Leung SW, Laughner E, Wenger RH, Gassmann M, Gearhart JD, Lawler AM, Yu AY, and Semenza GL. Cellular and developmental control of $\mathrm{O}_{2}$ homeostasis by hypoxia-inducible factor $1 \alpha$. Genes Dev 12: 149-162, 1998.

31. Jung SK, Trimarchi JR, Sanger RH, and Smith PJS. Development and application of a self-referencing glucose microsensor for the measurement of glucose consuption by pancreatic beta-cells. Anal Chem 73: $3759-$ 3767, 2001.

32. Kotch LE, Iyer NV, Laughner E, and Semenza GL. Defective vascularization of HIF-1alpha-null embryos is not associated with VEGF deficiency but with mesenchymal cell death. Dev Biol 209: 254-267, 1999.

33. Land SC, Porterfield DM, Sanger RH, and Smith PJS. The selfreferencing oxygen-selective microelectrode: Detection of transmembrane oxygen flux from single cells. J Exp Biol 202: 211-218, 1999.

34. Maltepe E, Schmidt JV, Baunoch D, Bradfield CA, and Simon MC. Abnormal angiogenesis and responses to glucose and oxygen deprivation in mice lacking the protein ARNT. Nature 386: 403-407, 1997.

35. McGee SL, Howlett KF, Starkie RL, Cameron-Smith D, Kemp BE, and Hargreaves M. Exercise increases nuclear AMPK alpha2 in human skeletal muscle. Diabetes 52: 926-928, 2003.

36. Mills JL, Baker L, and Goldman AS. Malformations in infants of diabetic mothers occur before the seventh gestational week: Implications for treatment. Diabetes 28: 292-293, 1979.

37. Miodovnik M, Mimouni F, Dignan PSJ, Berk MA, Ballard JL, Siddiqi TA, Khoury J, and Tsang RC. Major malformations in infants of IDDM women: Vasculopathy and early first-trimester poor glycemic control. Diabetes Care 11: 713-718, 1988.

38. Paddenberg R, Ishaq B, Goldenberg A, Faulhammer P, Rose F, Weissmann N, Braun-Dullaeus RC, and Kummer W. Essential role of complex II of the respiratory chain in hypoxia-induced ROS generation in the pulmonary vasculature. Am J Physiol Lung Cell Mol Physiol 284: L710-L719, 2003.

39. Page EL, Robitaille GA, Pouyssegur J, and Richard DE. Induction of hypoxia-inducible factor-1alpha by transcriptional and translational mechanisms. J Biol Chem 277: 48403-48409, 2002.

40. Phelan S and Loeken M. Identification of a new binding motif for the paired domain of Pax-3 and unusual characteristics of spacing and of bipartite recognition elements on binding and transcription activation. J Biol Chem 273: 19153-19159, 1998.

41. Phelan SA, Ito M, and Loeken MR. Neural tube defects in embryos of diabetic mice: Role of the Pax-3 gene and apoptosis. Diabetes 46: 1189-1197, 1997.

42. Reece E, Homko C, Wu U, and Wiznitzer A. The role of free radicals and membrane lipids in diabetes-induced congenital malformations. J Soc Gynecol Investig 5: 178-187, 1998.

43. Richard DE, Berra E, and Pouyssegur J. Nonhypoxic pathway mediates the induction of hypoxia-inducible factor 1alpha in vascular smooth muscle cells. J Biol Chem 275: 26765-26771, 2000.

44. Rodesch F, Simon P, Donner C, and Jauniaux E. Oxygen measurements in endometrial and trophoblastic tissues during early pregnancy. Obstet Gynecol 80: 283-285, 1992.

45. Semenza GL, Roth PH, Fang HM, and Wang GL. Transcriptional regulation of genes encoding glycolytic enzymes by hypoxia-inducible factor 1. J Biol Chem 269: 23757-23763, 1994.

46. Sivan E, Lee YC, Wu YK, and Reece EA. Free radical scavenging enzymes in fetal dysmorphogenesis among offspring of diabetic rats. Teratology 56: 343-349, 1997.

47. Sivan E, Reece EA, Wu YK, Homko CJ, Polansky M, and Borenstein M. Dietary vitamin E prophylaxis and diabetic embryopathy: morphologic and biochemical analysis. Am J Obstet Gynecol 175: 793-799, 1996.

48. Smith PJS. The non-invasive probes: tools for measuring transmembrane ion flux. Nature 378: 645-646, 1995.

49. Smith PJS, Hammar K, Porterfield DM, Sanger RH, and Trimarchi JR. A self-referencing, non-invasive, ion-selective electrode for single cell detection of trans-plasma membrane calcium flux. Microsc Res Tech 46: 398-417, 1999 .

50. Tian H, Hammer RE, Matsumoto A, Russell DW, and McKnight SL. The hypoxia-responsive transcription factor EPAS1 is essential for catecholamine homeostasis and protection against heart failure during embryonic development. Genes Dev 12: 3320-3324, 1998.

51. Towner D, Kjos SL, Leung B, Montoro MM, Xiang A, Mestman JH, and Buchanan TA. Congenital malformations in pregnancies complicated by NIDDM. Diabetes Care 18: 1446-1451, 1995.

52. Turrens JF, Alexandre A, and Lehninger AL. Ubisemiquinone is the electron donor for superoxide formation by complex III of heart mitochondria. Arch Biochem Biophys 237: 408-414, 1985.

53. Wentzel P, Ejdesjo A, and Eriksson UJ. Maternal diabetes in vivo and high glucose in vitro diminish GAPDH activity in rat embryos. Diabetes 52: 1222-1228, 2003.

54. Wentzel P, Thunberg L, and Eriksson UJ. The teratogenic effect of diabetic serum is prevented by supplementation of superoxide dismutase and N-acetylcysteine in rat embryo culture. Diabetologia 40: 7-14, 1997.

55. Williamson JR, Chang K, Frangos M, Hasan HS, Ido Y, Kawamura T, Nyengaard JR, van den Enden M, Kilo C, and Tilton RG. Hyperglycemic pseudohypoxia and diabetic complications. Diabetes 42: 801813, 1993.

56. Yang X, Borg LA, and Eriksson UJ. Altered metabolism and superoxide generation in neural tissue of rat embryos exposed to high glucose. Am J Physiol Endocrinol Metab 272: E173-E180, 1997.

57. Yao TP, Oh SP, Fuchs M, Zhou ND, Ch'ng LE, Newsome D, Bronson RT, Li E, Livingston DM, and Eckner R. Gene dosage-dependent embryonic development and proliferation defects in mice lacking the transcriptional integrator p300. Cell 93: 361-372, 1998. 